\title{
A photo-physical and electrochemical impedance spectroscopy study on the quasi-solid state dye-sensitized solar cells based on poly(vinylidene fluoride-co-hexafluoropropylene)
}

\author{
Kun-Mu Lee ${ }^{\mathrm{a}}$, Vembu Suryanarayanan ${ }^{\mathrm{b}}$, Kuo-Chuan $\mathrm{Ho}^{\mathrm{a}, \mathrm{c}, *}$ \\ a Institute of Polymer Science and Engineering, National Taiwan University, Taipei 10617, Taiwan \\ ${ }^{\mathrm{b}}$ Electro Organic Division, Central Electrochemical Research Institute, Karaikudi 630006, India \\ c Department of Chemical Engineering, National Taiwan University, Taipei 10617, Taiwan
}

\section{A R T I C L E I N F O}

\section{Article history:}

Received 5 June 2008

Received in revised form 28 July 2008

Accepted 29 July 2008

Available online $\mathrm{xxx}$

\section{Keywords:}

Gel polymer electrolyte

Dye-sensitized solar cells

PVDF-HFP

EIS

\begin{abstract}
A B S T R A C T
Quasi-solid state dye-sensitized solar cells (DSSCs) were fabricated with poly(vinylidene fluoride-cohexafluoropropylene) (PVDF-HFP) in methoxy propionitrile (MPN) as gel polymer electrolyte (GPE), tetrabutylammonium iodide (TBAI)/iodine $\left(\mathrm{I}_{2}\right)$ as redox couple, 4 -tertiary butyl pyridine (TBP) as additive and silica nanoparticles as fillers. The energy conversion efficiency of the cell with $5 \mathrm{wt} \%$ PVDF-HFP is comparable to that one obtained in liquid electrolyte system. Solar cell containing PVDF-HFP with $0.8 \mathrm{M}$

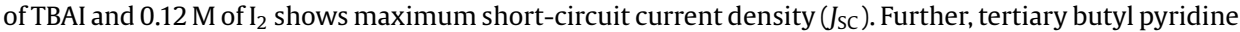
(TBP) has little effect in improving the performance of the solar cell. Moreover, the addition of $1 \mathrm{wt} \%$ silica nanoparticles is found to improve the at-rest durability and the performance of the solar cell. The transient photovoltage and photocurrent measurements were employed to find out the electron lifetimes in $\mathrm{TiO}_{2}$ electrode with different weight percentages of PVDF-HFP, various concentrations of $I_{2}$ and durability of the cell storage at $70^{\circ} \mathrm{C}$. A photocurrent density of $14.04 \mathrm{~mA} \mathrm{~cm}^{-2}$, an open-circuit voltage of $0.71 \mathrm{~V}$, a fill factor of 0.598 and an overall conversion efficiency of $5.97 \%$ under $100 \mathrm{~mW} \mathrm{~cm}^{-2}$ was observed for the best performance of a solar cell in this work.
\end{abstract}

Crown Copyright $\odot 2008$ Published by Elsevier B.V. All rights reserved.

\section{Introduction}

Dye-sensitized solar cells (DSSCs), developed by Grätzel et al., converts sunlight to electricity with high conversion efficiency of $11 \%[1,2]$. The liquid electrolyte, usually employed in the DSSC $\left(\mathrm{I}^{-} / \mathrm{I}_{3}^{-}\right.$redox couple dissolved in an organic solvent) is sandwiched between anode material (nanocrystalline dye-sensitized $\mathrm{TiO}_{2}$ ) and cathode material (Pt sputtered on fluorine-doped tin oxide glass (FTO glass) [3]. However, liquid electrolytes can lead to major technological problems associated with performance limitation in long-term operation due to sealing difficulties. In order to overcome this, considerable efforts have been made to replace the liquid electrolytes by solid-state conductors such as p-type inorganic semiconductors [4,5] or with hole conductors [6-9]. However, the conversion efficiency of the DSSC becomes very low due to the imperfect contact between the dye anchored electrode and the hole conductor.

\footnotetext{
* Corresponding author at: Department of Chemical Engineering, National Taiwan University, Taipei 10617, Taiwan. Tel.: +8862 3366 3019; fax: +8862 23623040.

E-mail address: kcho@ntu.edu.tw (K.-C. Ho)
}

The other way to overcome this disadvantage is to use gel polymer material as quasi-solid electrolytes in suitable plasticizers. Various gel polymer electrolytes (GPEs)-based DSSCs such as poly(acrylonitrile) [10-15], poly(ethyleneoxide) [16-18], poly(oligoethyleneglycol methacrylate) [19], poly(siloxane-coethylene oxide) [20], poly(butylacrylate) [21], polyvinylidene fluoride-co-hexafluoro propylene (PVDF-HFP) $[22,23]$ and chemically cross-linked $[24,25]$ with different plasticizers have been investigated in the literatures.

Among the various GPEs mentioned above, PVDF-HFP-based electrolyte shows relatively high ionic conductivities at ambient temperatures and it has been successfully used as the quasi-solid state materials in combination with room temperature ionic liquids showing good conversion efficiencies [26-28]. Further, fluorinated polymers are potentially stable even in the presence of $\mathrm{TiO}_{2}$ and Pt nanoparticles, which underline their suitability as a quasi-solid electrolyte in terms of long-term stability of the DSSC [29,30]. Submicrometer-sized anatase and graphite particles can be dispersed in these electrolyte media to form stable colloidal solution [31]. Among the various choices of filler, silica nanoparticles are the most promising one for improving the cell performance [23]. The incorporation of small amounts of these nanoparticles into the polymer 
matrix has been shown to significantly alter the mechanical properties of the composite. In addition, they can drastically increase the solvent retention of gels due to physical and chemical interactions between the solvent and nanoparticles [27]. It is also of interest to note that nanoparticles tend to prevent electrolyte/electrode interfacial resistance, which increases over time [27,32].

The electron transport dynamics and recombination kinetics are major factors related to the overall efficiency of dye-sensitized nanocrystalline $\mathrm{TiO}_{2}$ solar cell [3,33-36]. Because the collection of injected electrons competes with recombination by oxidized dye and redox couple, slow electrons transport may lead to low charge collection as well as conversion efficiency. Therefore, in this paper, the influences of different weight percentages of this fluorine polymer and silica nanoparticles as well as the effect of $\mathrm{I}_{2}$ concentration on the photocurrent-voltage characteristics of the DSSCs were found out along with the resultant changes in electron transport properties of the nanostructured $\mathrm{TiO}_{2}$ by electrochemical impedance spectroscopy (EIS), and laser induced transient photovoltage and photocurrent measurements. In addition, the photoelectrochemical properties of the DSSCs containing PVDF-HFP GPEs with various storage times at $70^{\circ} \mathrm{C}$ were also investigated.

\section{Experimental}

Anhydrous $\mathrm{I}_{2}$, ethanol (99.5\%), tertiary butanol, and 4-tertiary butyl pyridine (TBP) were obtained from Merck, and titanium (IV) tetraisopropoxide (TTIP) (>98\%) was purchased from Acros; all were used as received. Methoxy propionitrile (MPN) and tertiary butanol were purchased from Merck and water molecules were removed by putting molecular sieves ( $4 \AA$ ) into the solvents. PVDFHFP (molecular weight $=400,000)$ and silica nanoparticles $(20 \mathrm{~nm})$ were obtained from Aldrich. Cis-Di(thiocyanato)bis(2,2'-bipyridyl$4,4^{\prime}$-dicarboxylate) ruthenium (II) (N3 dye) is a commercial product of Solaronix (Aubonne, Switzerland).

The $\mathrm{TiO}_{2}$ electrodes were prepared by sol-gel process in acid medium followed by autoclaving of titanium (IV) isopropoxide at $240{ }^{\circ} \mathrm{C}$ for $12 \mathrm{~h}$ as described elsewhere [37]. The autoclaved solution was concentrated to $13 \mathrm{wt} \%$ and $\mathrm{TiO}_{2}$ paste prepared by adding $30 \mathrm{wt} \%$ (with respect to $\mathrm{TiO}_{2}$ ) of PEG with the corresponding molecular weights of 200,000 to the above solution in order to control the pore diameters and to prevent the film from cracking during drying. Here, high molecular weight PEG was used in the $\mathrm{TiO}_{2}$ paste, which could enlarge the pore diameter of the $\mathrm{TiO}_{2}$ film and lead the high viscosity GPEs to penetrate easily into the inner pores.

The $\mathrm{TiO}_{2}$ paste was coated on a fluorine-doped tin oxide (FTO) glass plate using glass rod (the sheet resistivity of FTO is $15 \Omega$ square ${ }^{-1}$ ). After this, these $\mathrm{TiO}_{2}$ electrodes were dried in the air at room temperature for $30 \mathrm{~min}$ followed by sintering at $500^{\circ} \mathrm{C}$ in a hot-oven at a rate of $5^{\circ} \mathrm{C} \mathrm{min}^{-1}$ for another $30 \mathrm{~min}$. An active area of $0.25 \mathrm{~cm}^{2}$ was selected from sintered $\mathrm{TiO}_{2}$ electrode and the electrodes were immersed in a $3 \times 10^{-4} \mathrm{M}$ solution of $\mathrm{N} 3$ dye containing acetonitrile and tertiary butanol (in the volume ratio of 1:1) for $24 \mathrm{~h}$. Pt (100 nm thick) sputtered on FTO was used here as the counter electrode.

GPE was prepared as follows: the required weight percentage of PVDF-HFP was added to the necessary concentration of $\mathrm{I}_{2} / \mathrm{TBAI}$ redox electrolyte in MPN and stirred at $70^{\circ} \mathrm{C}$ for $8 \mathrm{~h}$. When the electrolyte was cooled down, it became gel and if needed, silica nanoparticles were added and used as such. For measuring at-rest stability, the cell was fabricated by keeping an ionomer resin (Surlyn 1702, Dupont, USA) between the two electrodes and two holes were made on the resin. The whole set-up was heated at $90^{\circ} \mathrm{C}$ on a hot plate till all the resin had been melted and the electrolyte was injected into the space between the electrodes through these two holes. Finally, these two holes were sealed completely by the Torr Seal ${ }^{\circledR}$ cement (Varian, USA). For other measurements, the gel electrolyte was heated at $70^{\circ} \mathrm{C}$ and sprayed on to the dyed $\mathrm{TiO}_{2}$ electrode immediately followed by clipping it with a Pt counter electrode.

The photoelectrochemical characterizations of the DSSCs were carried out by using an AM 1.5 simulated light radiation. The light source was a 450-W Xe lamp (\#6266, Oriel, USA) equipped with a water-based infrared (IR) filter and an AM 1.5 filter (\#81075, Oriel). Conductivity measurement of GPE was performed by impedance spectroscopy with two Pt electrodes conductance cell where the area of the each Pt electrode is $1 \mathrm{~cm}^{2}$ and the distance between the two electrodes is $1 \mathrm{~cm}$. The cell constant is 0.54 as calibrated from the standard aqueous $\mathrm{KCl}$ solution $\left(12.9 \mathrm{mS} \mathrm{cm}^{-1}\right)$.

The lifetime of injected electron in the $\mathrm{TiO}_{2}$ film before recombination with oxidized dye or $\mathrm{I}_{3}^{-}$can be measured by transient photovoltage under open-circuit conditions [33]. The transients photovoltage of assembled devices were recorded with a digital oscilloscope (model LT322, LeCroy, USA). Pulsed laser excitation was applied by a frequency-doubled Q-switched Nd:YAG laser (Spectra-Physics laser, model Quanta-Ray GCR-3-10, SpectraPhysics laser) with 2-Hz repetition rate at $532 \mathrm{~nm}$, and 7-ns pulse width at half-height. The beam size was slightly larger than $0.25 \mathrm{~cm}^{2}$ to cover the area of the device with an incident energy of $1 \mathrm{~mJ} \mathrm{~cm}^{-2}$. The average electron lifetime can be approximately estimated by fitting a decay of the open-circuit voltage transient with $\exp \left(-t \tau_{\mathrm{e}}{ }^{-1}\right)$, where $t$ is time and $\tau_{\mathrm{e}}$ is an average time constant before recombination.

Electron diffusion coefficient was $\left(D_{\mathrm{e}}\right)$ approximately estimated by fitting a decay of the transient current with $\exp \left(-t \tau_{C}{ }^{-1}\right)$, which was derived from the equation of continuity for electrons in the conduction bond [35], where $t$ and $\tau_{\mathrm{C}}$ are the time and average time constant, respectively. Then, the apparent diffusion constant can be estimated using Eq. (1):

$D_{\mathrm{e}}=w^{2} 2.35^{-1} \tau_{\mathrm{C}}^{-1}$

where $w$ is the film thickness and the factor 2.35 arises from the geometry of the diffusion problem [36].

Photoelectrochemical characteristics and the electrochemical impedance spectroscopy (EIS) measurements of the DSSCs were recorded with a potentiostat/galvanostat (PGSTAT 30, Autolab, Eco-Chemie, the Netherlands) under $100 \mathrm{~mW} \mathrm{~cm}^{-2}$. The frequency range explored was from $10 \mathrm{mHz}$ to $65 \mathrm{kHz}$. The applied bias voltage and ac amplitude were set at open-circuit voltage of the DSSCs and $10 \mathrm{mV}$ between the $\mathrm{FTO} / \mathrm{Pt}$ counter electrode and the $\mathrm{FTO} / \mathrm{TiO}_{2} /$ dye working electrode, respectively, starting from the short-circuit condition [38]. The impedance spectra were analyzed by an equivalent circuit model interpreting the characteristics of the DSSCs $[28,29]$.

\section{Results and discussion}

The photovoltaic characteristics of the DSSCs obtained by incorporating different weight percentages of PVDF-HFP containing MPN as the plasticizer at constant light illumination of $100 \mathrm{~mW} \mathrm{~cm}^{-2}$ were shown in Table 1 . The concentrations of TBAI $(0.4 \mathrm{M})$ and $\mathrm{I}_{2}(0.04 \mathrm{M})$ were kept as constant at beginning. From this table, it is noted that the $J_{S C}$ and the conversion efficiency of the DSSCs decrease with the increase in weight percentage of PVDFHFP, while the $V_{\mathrm{OC}}$ remains constant. This phenomenon may be correlated with the ionic conductivity. Ionic conductivity $(\sigma)$ of the polymer electrolyte can be written as

$\sigma=n e \mu$ 
Table 1

The electrolyte parameter and the cell performances of the DSSCs based on gel polymer electrolytes with various wt\% of PVDF-HFP

\begin{tabular}{|c|c|c|c|c|c|c|}
\hline PVDF-HFP (wt\%) & Conductivity $\left(\mathrm{mS} \mathrm{cm}^{-1}\right)^{\mathrm{b}}$ & $\tau_{\mathrm{e}}(\mathrm{ms})^{\mathrm{c}}$ & $J_{\mathrm{SC}}\left(\mathrm{mAcm}^{-2}\right)$ & $V_{\text {OC }}(\mathrm{V})$ & $\eta(\%)$ & FF \\
\hline 0 & 6.10 & 1.40 & 11.24 & 0.702 & 3.93 & 0.497 \\
\hline 5 & 5.71 & 2.75 & 10.96 & 0.708 & 3.71 & 0.478 \\
\hline 7 & 5.63 & 2.79 & 10.80 & 0.697 & 3.24 & 0.430 \\
\hline 9 & 5.18 & 2.71 & 9.00 & 0.697 & 2.68 & 0.428 \\
\hline
\end{tabular}

a The electrolytes were composed of $0.4 \mathrm{M} \mathrm{TBAI} / 0.04 \mathrm{M} \mathrm{I}_{2}$ in MPN with various wt\% PVDF-HFP.

b Measured at $25^{\circ} \mathrm{C}$.

c Electron lifetime measured by laser transient photovoltage.

where $n$ denotes carrier concentration, $e$ is the charge and $\mu$ is ionic mobility [38]. The increase in the polymer content increases the viscosity of the gel electrolytes, which lowers the conductivity. When the conductivity decreases, the ionic mobility as well as the diffusion coefficient of $\mathrm{I}^{-} / \mathrm{I}_{3}^{-}$naturally decreases. The decrease in diffusion coefficient reduces the supply of $\mathrm{I}_{3}^{-}$to the Pt counter electrode causing a depletion of $\mathrm{I}_{3}^{-}$at the electrode surface and hence decreases the $J_{S C}$ and FF of the DSSC [28]. The $V_{\mathrm{OC}}$, a difference between Fermi level of $\mathrm{TiO}_{2}$ and redox potential of electrolyte, is influenced mainly by the major ratio of $\mathrm{I}^{-} / \mathrm{I}_{3}^{-}$. In this, $\mathrm{I}^{-} / \mathrm{I}_{3}^{-}$molar ratio is independent of the polymer concentration and thus the $V_{\mathrm{OC}}$ shows similar values [40].

Laser pulse induced transient photovoltage obtained for mesoporous $\mathrm{TiO}_{2}$ electrode containing different weight percentages of PVDF-HFP electrolyte is shown in Fig. 1 and the corresponding recombination electron lifetimes $\left(\tau_{\mathrm{e}}\right)$ calculated from the curve fitting is also shown in Table 1 . The $\tau_{\mathrm{e}}$ increases from 1.4 to $2.75 \mathrm{~ms}$ when $5 \%$ of PVDF-HFP electrolyte was added to the liquid electrolyte. This dramatic change shows that electron recombination on $\mathrm{TiO}_{2}$ electrode is retarded by the incorporation of PVDF-HFP in electrolyte. However, further addition of polymer results in little effect on the electron lifetime. From the above results, an optimum weight percentage value of PVDF-HFP (5\%) have been taken for further studies.

Fig. 2a depicts the dependence of the ionic conductivity of TBAI and the $J_{S C}$ of the DSSC on the different concentrations of TBAI. (The concentration of $\mathrm{I}_{2}$ was kept as $0.08 \mathrm{M}$.) Both the ionic conductivity of TBAI and the $J_{S C}$ of the DSSC increased linearly with the increase in the concentration of TBAI and these two parameters saturated at $0.8 \mathrm{M}$ of TBAI. Further increase in the concentration of TBAI led to decrease in the $J_{S C}$ of the DSSC. On the other hand, the variation in the $V_{\mathrm{OC}}$ of the DSSC was found to be very little. As a result of this, the optimum concentration of TBAI should be in taken as $0.8 \mathrm{M}$, in terms of the cell performance.

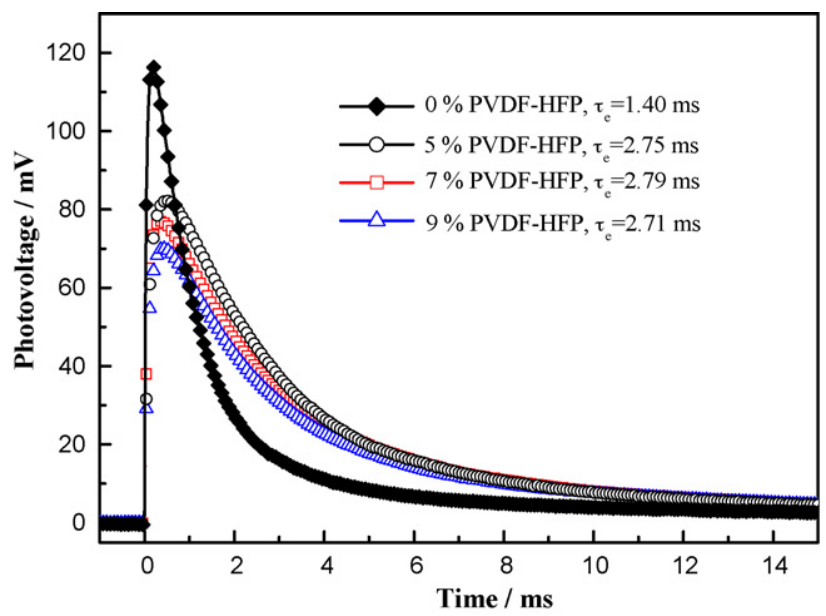

Fig. 1. Electron lifetimes in the $\mathrm{TiO}_{2}$ electrodes of the DSSCs with different wt\% of PVDF-HFP in electrolytes.
In a similar manner, the photocurrent density of the DSSC was optimized for different concentrations of $\mathrm{I}_{2}$. The relationship between the conductivity of different concentrations of $\mathrm{I}_{2}$ against the $J_{S C}$ of the DSSCs is shown in Fig. 2b. It is noted that the addition of small amount of $\mathrm{I}_{2}$ into the electrolyte results in the remarkable improvement of the conductivity and the $J_{\mathrm{SC}}$ of the DSSC. The results show that the existence of $\mathrm{I}_{2}$ causes drastic improvement in the charge transfer, which are able to work in the microscopic molecular networks of the polymers. Such a non-linear increase of the conductivity at high concentration of $\mathrm{I}_{2}(0.4 \mathrm{M})$ may be associated with formation of poly(iodides) $\left(\mathrm{I}_{2 n+1}^{-}\right)$in the electrolyte, as confirmed by Yanagida et al.[41]. They suggested that the Grotthuss-type charge transfer mechanism (poly(iodide) bond exchange mechanism), where electron exchange between $\mathrm{I}^{-}, \mathrm{I}_{3}^{-}$and poly(iodides) through chemical bond were coupled, which contribute to the effective conductance of the gel electrolyte, rationalizing the high conductivity of the electrolyte in the DSSCs. In those studies, the formation
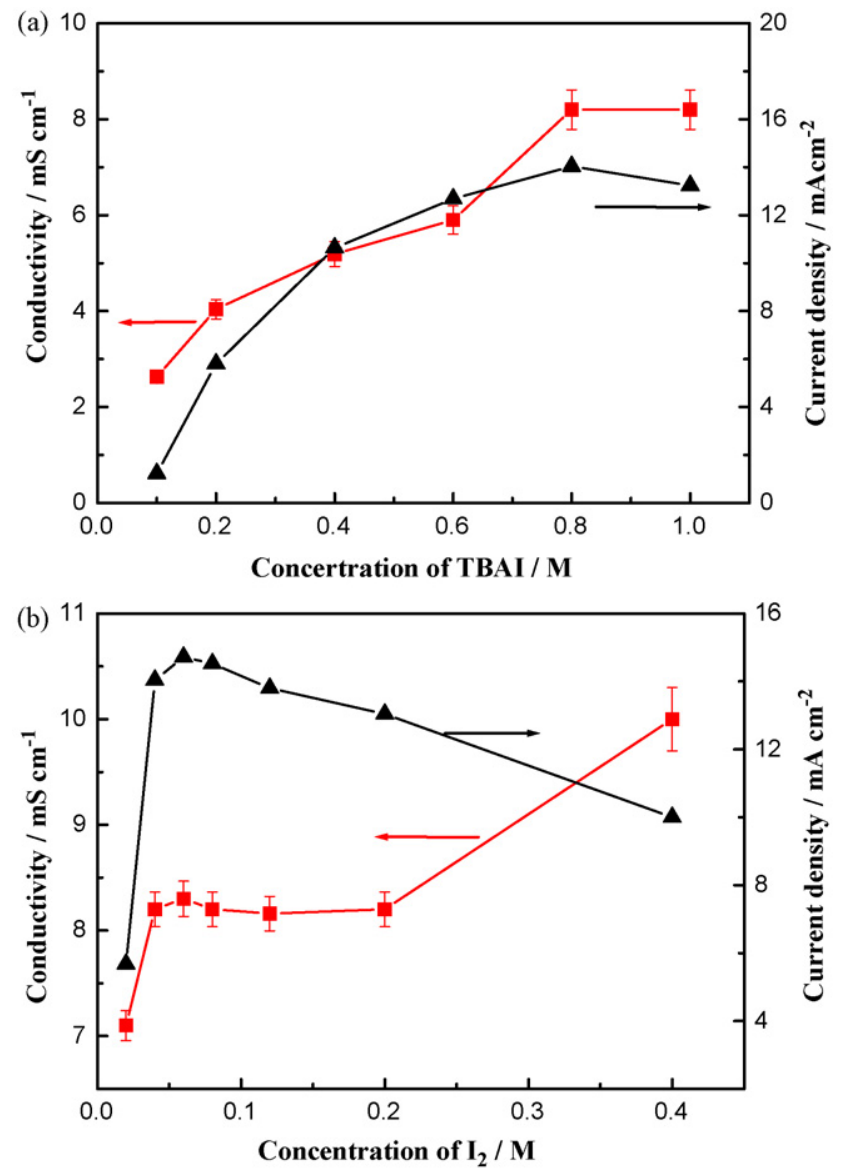

Fig. 2. Conductivities of electrolytes and the current densities of the DSSCs based on various concentrations of (a) TBAI and (b) $\mathrm{I}_{2}$, respectively. 


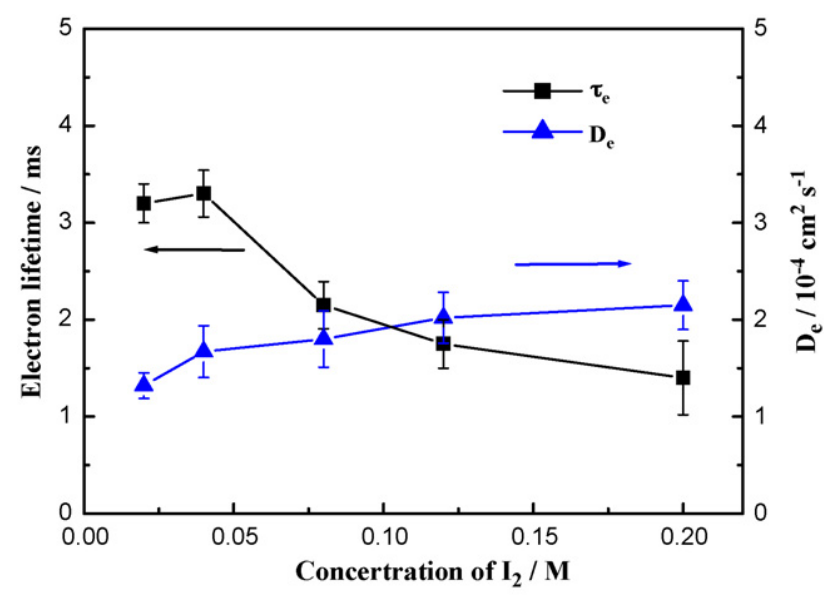

Fig. 3. Electron lifetimes and electron diffusion coefficients based on various concentrations of $\mathrm{I}_{2}$.

of the poly(iodides) was also confirmed by Raman spectroscopy [41].

Nevertheless, the $J_{S C}$ of the DSSC increases with the increase in the concentration of $\mathrm{I}_{2}$ from 0.02 to $0.08 \mathrm{M}$ and further increase results in the decrease of the $J_{S C}$. The explanation may be given by considering the following redox reactions:

$\mathrm{I}_{2}+\mathrm{I}^{-} \leftrightarrow \mathrm{I}_{3}^{-}$

$\mathrm{I}_{3}^{-}+2 \mathrm{e}^{-} \rightarrow 3 \mathrm{I}^{-} \quad$ (at Pt electrode)

$3 \mathrm{I}^{-} \rightarrow \mathrm{I}_{3}^{-}+2 \mathrm{e}^{-} \quad\left(\right.$ at $\mathrm{TiO}_{2}$ anode $)$

$\mathrm{I}_{3}^{-}+2 \mathrm{e}^{-}(\mathrm{CB}) \rightarrow 3 \mathrm{I}^{-} \quad$ (side reaction at $\mathrm{TiO}_{2}$ anode)

According to reaction (3), increase of $\mathrm{I}_{2}$ concentration acts in favor of $\mathrm{I}_{3}^{-}$as $\mathrm{I}^{-}$is much higher than that of $\mathrm{I}_{2}$. Since a critical concentration level of $\mathrm{I}_{3}^{-}$is necessary for the cell functioning at the beginning, reaction (4) and (5) proceeds effectively and the $J_{S C}$ increases and saturates at once. However, further increase in the concentration of $\mathrm{I}_{2}$ results in favor of reaction (6) decreasing the performance of the DSSCs. Furthermore, $\mathrm{I}_{2}$ also absorbs some visible lights from the wavelength of 400 to $500 \mathrm{~nm}$, suppressing the visible light absorption by the sensitizer [42].

Laser pulse induced transient photovoltages and photocurrents were obtained for mesoporous $\mathrm{TiO}_{2}$ electrode containing different concentrations of $\mathrm{I}_{2}$ with a fixed $\mathrm{I}^{-}$concentration. Measured electron lifetimes and electron diffusion coefficients were plotted as a function of increase in the concentration of $\mathrm{I}_{2}$ and are shown in Fig. 3. The electron lifetime decreases with increasing of concentration of $\mathrm{I}_{2}$ from 0.0 to $0.20 \mathrm{M}$. This shows that recombination is raised with increase in concentration of $\mathrm{I}_{2}$. Enough $\mathrm{I}^{-}$ ions $(0.8 \mathrm{M})$ are present to reduce the dye cations, so that the decrease of lifetime should be directly related to increase of $\mathrm{I}_{3}^{-}$. Meanwhile, the increase of $D_{\mathrm{e}}$ with increase of $\mathrm{I}_{2}$ is interpreted with ambipolar diffusion, which is related with the diffusion of electrons and $\mathrm{I}_{2}$, and the concentrations of these charges [43]. This approaches the electron diffusion coefficients in the $\mathrm{TiO}_{2}$ film with increase in the concentration of $\mathrm{I}_{2}$. The electron diffusion coefficient at this $\mathrm{I}_{2}$ concentration $(0.20 \mathrm{M})$ is found to be maximum (about $3.0 \times 10^{-4} \mathrm{~cm}^{2} \mathrm{~s}^{-1}$ ), which is higher than the effective diffusion constant of $4.4 \times 10^{-6} \mathrm{~cm}^{2} \mathrm{~s}^{-1}$ for $\mathrm{I}_{3}^{-}$within the pores of the $\mathrm{TiO}_{2}$ film [44].

Figs. 4 and 5 show the electrochemical impedance spectra of the DSSCs containing different concentrations of TBAI and $\mathrm{I}_{2}$ with 5\% PVDF-HFP/MPN, respectively. The equivalent circuit employed for the curves fitted the impedance spectra of the DSSCs by Z-view
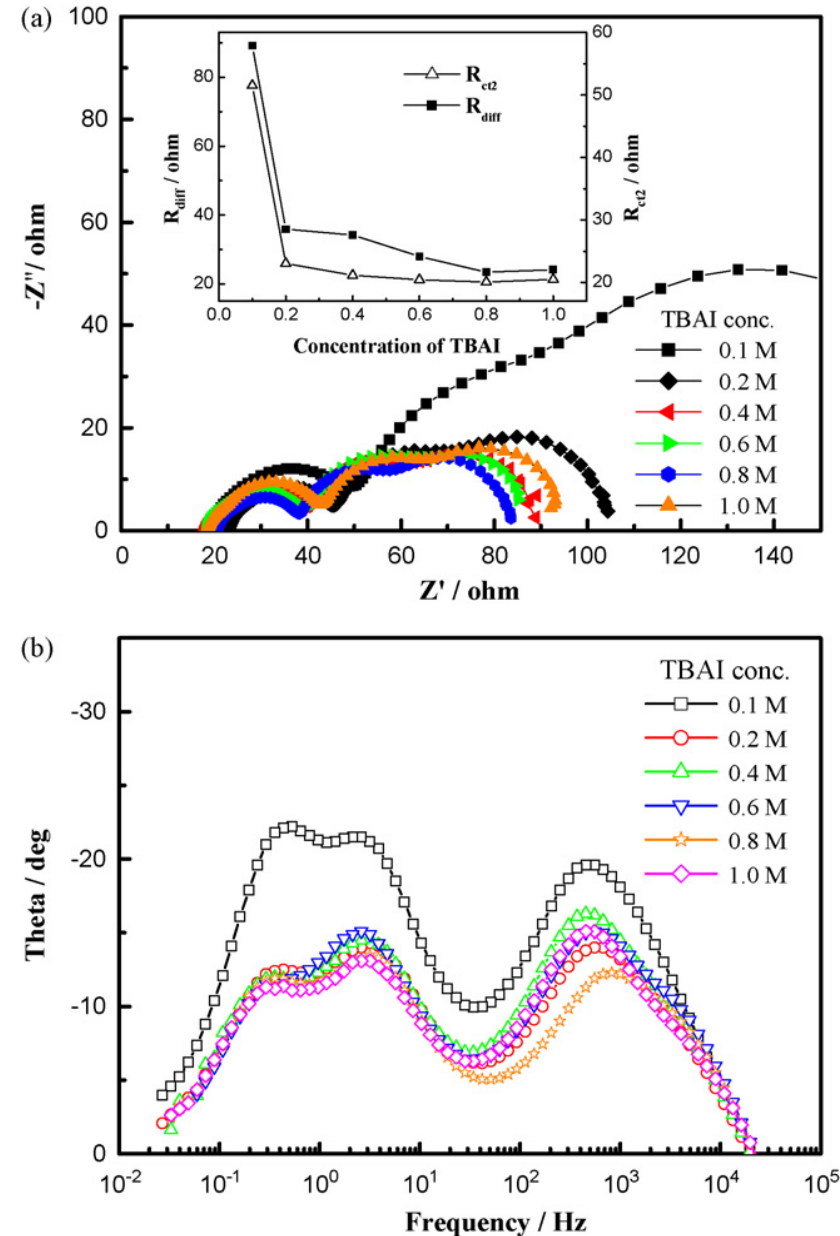

Fig. 4. (a) Nyquist plots and (b) Bode phase plots based on different concentrations of TBAI

software are shown as inset in Figs. 4a and 5a. All the spectra exhibit three semicircles, which are assigned to electrochemical reaction at $\mathrm{Pt}$ counter electrode, charge transfer at the $\mathrm{TiO}_{2} /$ dye/electrode and Warburg diffusion process of $\mathrm{I}^{-} / \mathrm{I}_{3}^{-}[38,39]$. Since, the resistance of the ITO as well as thicknesses of the Pt and $\mathrm{TiO}_{2}$ film was kept constant, there is only little change in their corresponding charge transfer resistances. However, charge transfer resistance $\left(R_{\mathrm{ct} 2}\right)$ and Warburg diffusion resistance $\left(R_{\text {diff }}\right)$ of the DSSCs differs very much with change in the concentrations of redox electrolyte. The plots of the $R_{\mathrm{ct} 2}$ and $R_{\mathrm{diff}}$ of the DSSCs vs. different concentrations of $\mathrm{I}_{2} / \mathrm{TBAI}$ are shown in as the inset. The $R_{\mathrm{ct} 2}$ and $R_{\mathrm{diff}}$ values both decrease with increase in the concentrations of both TBAI and $\mathrm{I}_{2}$; however, saturate at $0.8 \mathrm{M}$ of TBAI and $0.1 \mathrm{M}$ of $\mathrm{I}_{2}$. The reduction of the $R_{\mathrm{ct} 2}$ value with the increase in the amount of TBAI suggests more electrons injection from dye molecules, increasing the electron concentration in $\mathrm{TiO}_{2}$, and thus improves the number of electron transferring at the interface of $\mathrm{TiO}_{2} /$ dye/electrolyte. Meanwhile, the reduction of the $R_{\mathrm{ct} 2}$ with the increase in the amount of TBAI takes place without changing of recombination characteristic frequency and this indicates that the injection of electrons in $\mathrm{TiO}_{2}$ can stay almost equal period in various concentration of TBAI used in the study (Fig. 4b). In addition, the frequency peaks in high-frequency regime $\left(10^{3}\right.$ to $\left.10^{5} \mathrm{~Hz}\right)$ shown in Bode phase plot corresponding to the electron transfer at the counter electrode $\left(\mathrm{I}_{3}^{-}+2 \mathrm{e}^{-}=3 \mathrm{I}^{-}\right)$also shift to a higher frequency with the increase of TBAI, suggesting the increase of redox reaction of $\mathrm{I}^{-} / \mathrm{I}_{3}^{-}$at $\mathrm{Pt}$ surface with the increase of TBAI. This reveals that the increase 

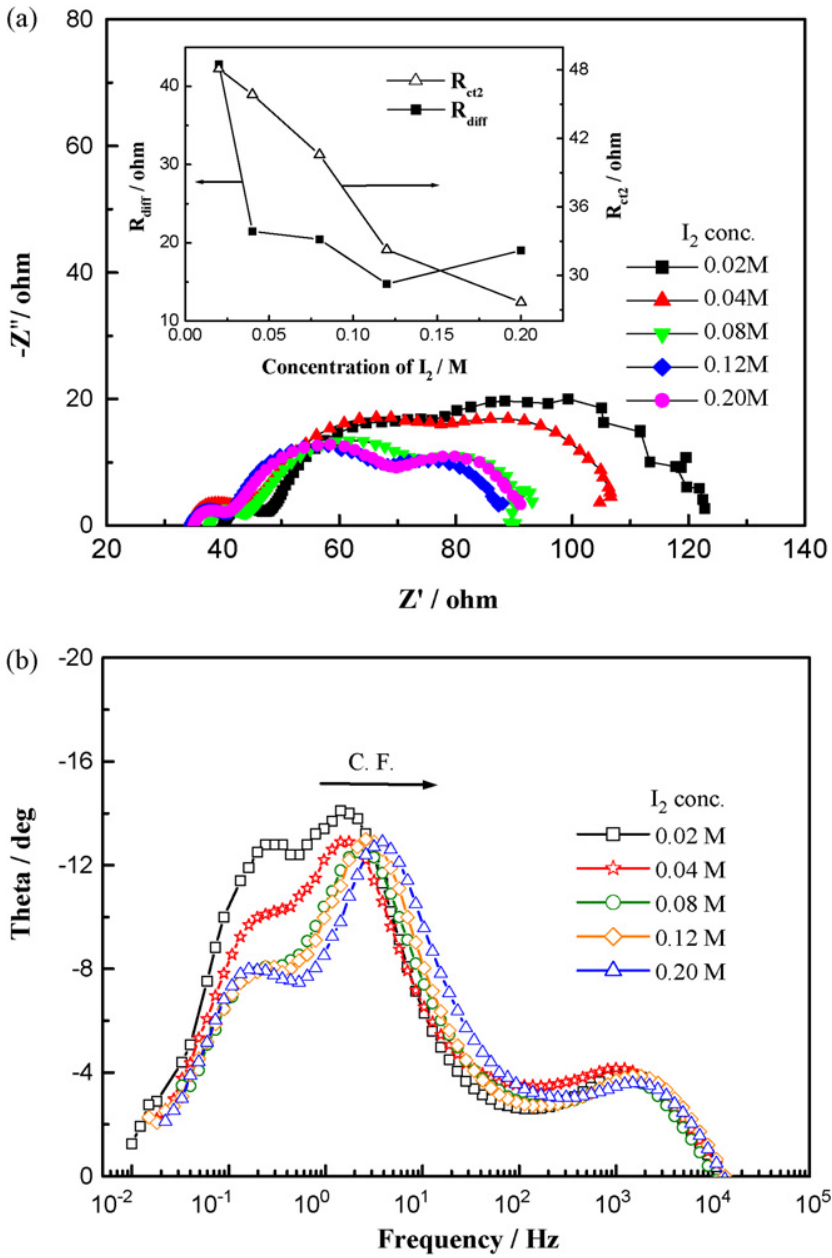

Fig. 5. (a) Nyquist plots and (b) Bode phase plots based on different concentrations of $\mathrm{I}_{2}$.

in the fill factor arises from faster electron transfer at the counter electrode.

Correspondingly, the characteristic frequency peaks (CF) of $\mathrm{TiO}_{2}$ shown in intermediate-frequency regime of Bode phase plot shift to a higher frequency with the increase of $\mathrm{I}_{2}$ concentration (Fig. 5b), indicating the decrease of electron lifetime with increase of $\mathrm{I}_{2}$. This is due to the difference in the local $\mathrm{I}_{3}^{-}$concentration. As indicated by Eq. (7), the higher local $\mathrm{I}_{3}^{-}$concentration produced in the porous $\mathrm{TiO}_{2}$ film under light is expected to accelerate the recapture of conduction band electrons and shortens their lifetime within the $\mathrm{TiO}_{2}$ electrode [45].

$J_{\mathrm{r}}=e k_{\mathrm{r}} c_{\mathrm{ox}}^{\gamma}\left(n^{\beta}-n_{0}^{\beta}\right)$

where $J_{\mathrm{r}}$ is the $\mathrm{I}_{3}^{-}$reduction current, $k_{\mathrm{r}}$ is the rate constant of the reduction reaction, and $c_{\mathrm{ox}}$ is the concentration of $\mathrm{I}_{3}^{-}$; exponents $\gamma$ and $\beta$ are the reaction orders for $\mathrm{I}_{3}^{-}$and electrons, respectively.

In order to get highly efficient DSSC, TBP is added into the electrolyte and the influence of its adsorption is mainly attributed to the negative shift of the $\mathrm{TiO}_{2}$ conduction band gap [46]. This phenomenon may be associated with the kind of coexisting cations. Table 2 shows photovoltaic parameters of DSSCs for different concentrations of TBP. The large increase of the $V_{\mathrm{OC}}$ was seen with increase of the concentration of TBP and this is correlated with the back electron transfer reaction, which is the reduction of $\mathrm{I}_{3}^{-}$ by an electron obtained from the conduction band of the $\mathrm{TiO}_{2}$. However, the $J_{S C}$ values decrease and as a result of this, there is
Table 2

The cell performance of the DSSCs containing various concentrations of TBP

\begin{tabular}{llllll}
\hline No. & $\begin{array}{l}\text { Concentration } \\
\text { of TBP }(\mathrm{M})\end{array}$ & JSC $\left(\mathrm{mA} \mathrm{cm}^{-2}\right)$ & $V_{\mathrm{OC}}(\mathrm{V})$ & $\eta(\%)$ & $\mathrm{FF}$ \\
\hline 1 & 0 & 14.52 & 0.641 & 4.19 & 0.450 \\
2 & 0.1 & 10.80 & 0.693 & 4.46 & 0.596 \\
3 & 0.3 & 10.20 & 0.715 & 4.17 & 0.572 \\
4 & 0.5 & 10.00 & 0.721 & 4.16 & 0.577 \\
5 & 0.7 & 9.52 & 0.731 & 4.03 & 0.579 \\
\hline
\end{tabular}

The electrolytes were composed of $0.8 \mathrm{M} \mathrm{TBAI} / 0.12 \mathrm{M} \mathrm{I}_{2}$ in MPN with 5 wt\% PVDFHFP.

not much change in the cell performance of the DSSCs. On the other hand, a good improvement in the fill factor was noted for the DSSCs by adding $0.1 \mathrm{M}$ of TBP and further increase produces nil effect. Hence, for further studies, an optimum concentration $0.1 \mathrm{M}$ of TBP was taken which yields the best photovoltaic parameters for the DSSC, i.e. $J_{\mathrm{SC}}, V_{\mathrm{OC}}$, fill factor (FF) and conversion efficiency of $10.80 \mathrm{mAcm}^{-2}, 0.693 \mathrm{~V}, 0.596$ and $4.46 \%$, respectively, under $100 \mathrm{~mW} \mathrm{~cm}^{-2}$.

As we told in Section 1, the incorporation of silica nanoparticles in polymer electrolyte yields higher ionic conductivity with improved cell retention. This could help in enhancing the cell performance, circumventing the sealing problem and further could increase the stability and lifetime of these devices. The temperature dependence of the conductivity of the different wt\% of $\mathrm{SiO}_{2}$ nanoparticles is shown in Fig. 6. It is noted that the ionic conductivity increases with the addition of $1 \%$ and $3 \%$ of $\mathrm{SiO}_{2}$ nanoparticles and further addition decreases the ionic conductivity slightly. The GPEs containing $1 \%$ and $3 \%$ nano- $\mathrm{SiO}_{2}$ particles increase the ionic conductivity owing to the decrease in the crystallinity of PVDF-HFP matrix and act as "solid plasticizer" capable of enhancing the ions transport properties. Li et al. [47] have studied the PVDF-HFP filled with different amounts of nanoparticles. They found that the crystallinity of polymer matrix decreased with the increase of mass fraction of nanoparticles due to their solid plasticization effect. Stephan et al. [48] have also revealed that the addition of fillers with Lewis acid surface groups usually leads to reduction in ion pairing and therefore to increase in the ion conductivity. Recently, Kang et al. [49] studied the quasi-solid-state DSSCs employing ternary component GPEs and they suggested that the $\mathrm{TiO}_{2}$ nanoparticles added to the GPE as a nanofiller can decrease the crystallinity of polymer and build a transfer channel for the redox couple, resulting in the increases of $J_{\mathrm{SC}}$ significantly.

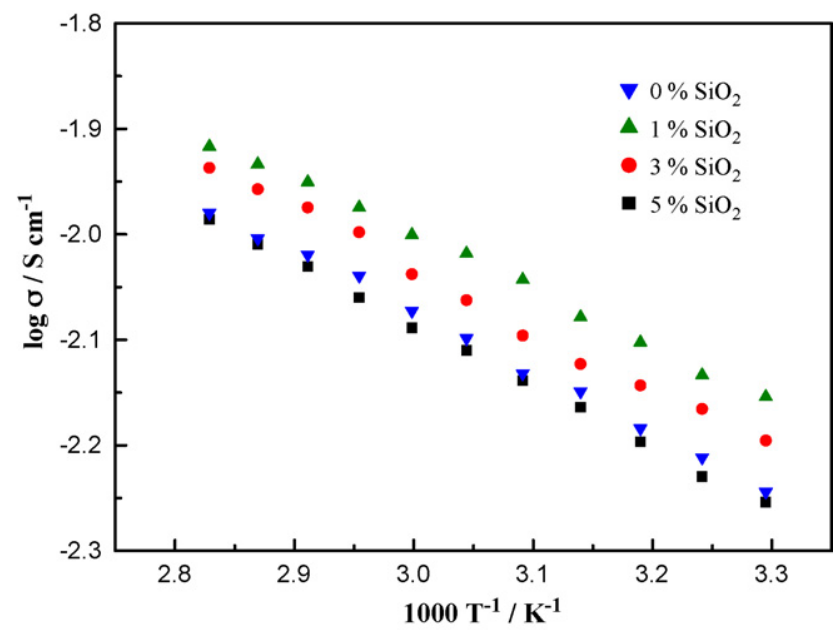

Fig. 6. Plot of conductivity vs. temperature with various wt $\%$ of nano- $\mathrm{SiO}_{2}$. 
Table 3

The electrolyte parameters and the cell performances of the DSSCs based on gel polymer electrolytes containing different wt\% of nano-SiO ${ }_{2}$

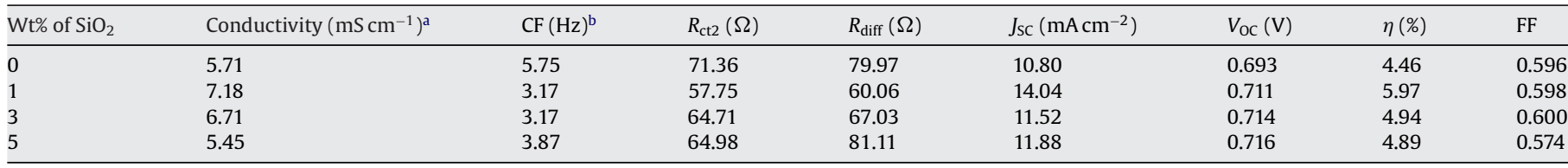

a Measured at $30^{\circ} \mathrm{C}$.

b Characteristic frequency peak of $\mathrm{TiO}_{2}$.

The decrease of ionic conductivity with $5 \%$ nano- $\mathrm{SiO}_{2}$ particles may be correlated with progressive decrease of ion motion inside the channels or aggregation of nanoparticles containing PVDF-HFP. From Fig. 6, the activation energy of conductivity $\left(E_{\mathrm{a}}\right)$ of each electrolyte system can be calculated by the slope of the curve according to the Arrhenious Eq. (8):

$\sigma=\sigma_{0} \exp \left(\frac{-E_{\mathrm{a}}}{R T}\right)$

where $R$ is the gas constant and $T$ is the temperature in $\mathrm{K}$. According to the free-volume model, the $E_{\mathrm{a}}$ is closely related to the mobility of carriers. The $E_{\mathrm{a}}$ for GPE with various amounts of nano- $\mathrm{SiO}_{2}$ are calculated to be ca. $15.6 \mathrm{~kJ} \mathrm{~mole}^{-1}$. In traditional organic liquid type electrolytes, the value of $E_{\mathrm{a}}$ lies between 1 and $5 \mathrm{~kJ} \mathrm{~mole}^{-1}$ [50]. The $E_{\mathrm{a}}$ is raised about one order magnitude in PVDF-HFP/nano-SiO ${ }_{2}$ GPE system, which indicates that there exists obviously an interaction
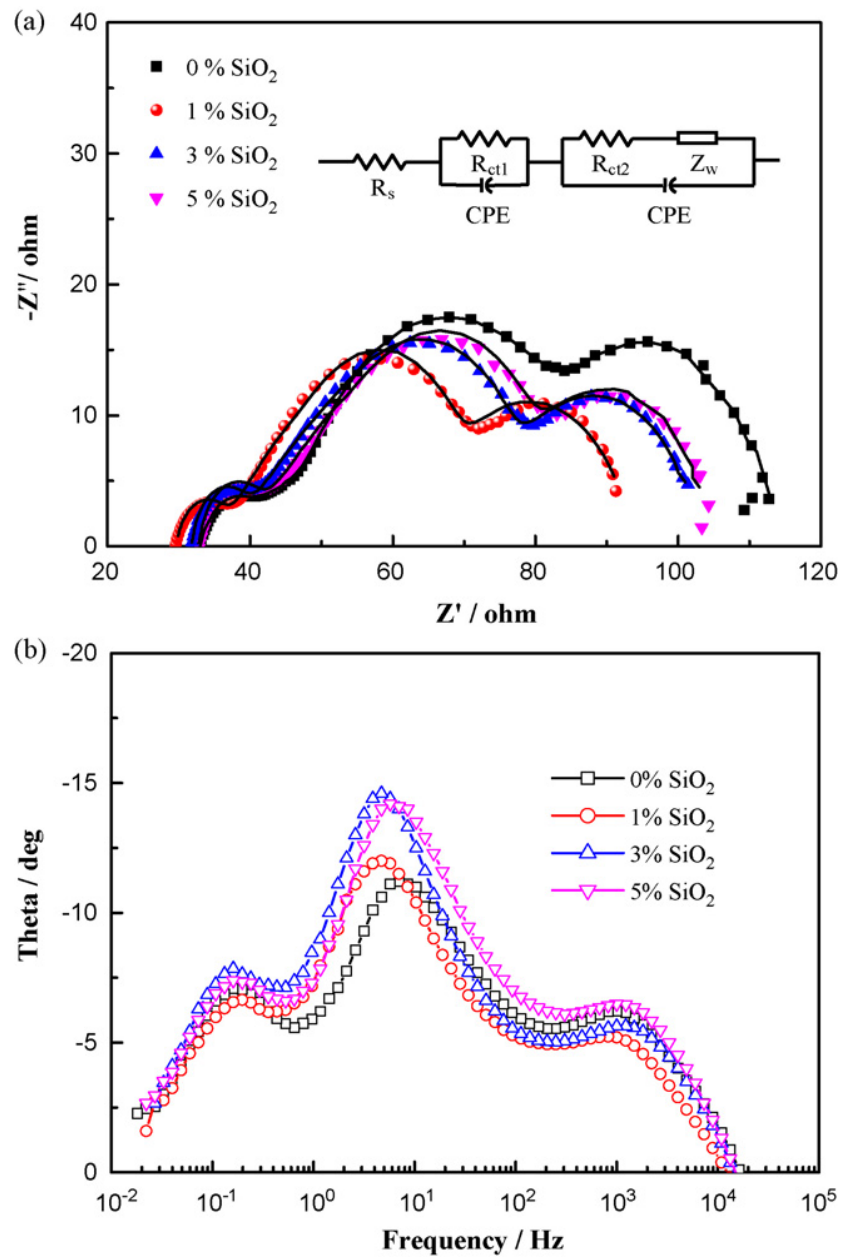

Fig. 7. (a) Nyquist plots (including fitting curves) and (b) Bode phase plots based on gel polymer electrolytes with various wt $\mathrm{SiO}_{2}$. between ions and polymer structures, resulting in the increase of the energy barrier for ion moving.

Table 3 shows the photoelectrochemical characteristics of the DSSCs obtained on the effect of addition of different wt\% of nano$\mathrm{SiO}_{2}$ into the PVDF-HFP electrolyte (the weight percentage of PVDF-HFP is $5 \%$ and the concentration ratio of TBAI $/ \mathrm{I}_{2}$ is $0.8 / 0.12 \mathrm{M}$ with $0.1 \mathrm{M}$ of TBP). The $J_{S C}$ of the DSSC increases appreciably with the addition of $1 \%$ nano-silica and decrease with the further addition, while there is no broad change in the $V_{\mathrm{OC}}$ and FF. This shows that $1 \%$ of nano- $\mathrm{SiO}_{2}$ is enough for getting good performance of the DSSCs. Meanwhile, the effect of nano-SiO ${ }_{2}$ addition in GPE was also studied by electrochemical impedance spectroscopy, and this is shown in Fig. 7a. In the Nyquist plot, $R_{\mathrm{ct} 2}$ and $R_{\mathrm{diff}}$ of the DSSC without nano- $\mathrm{SiO}_{2}$ are both larger than that with nano- $\mathrm{SiO}_{2}$ in $\mathrm{GPE}$, and the $R_{\mathrm{ct} 2}$ and the $R_{\mathrm{diff}}$ of the DSSC with $1 \%$ nano- $-\mathrm{SiO}_{2}$ are the smallest. Further, the characteristic frequency peaks of $\mathrm{TiO}_{2}$ based on GPE containing nano-SiO ${ }_{2}$ shifts to lower frequency obtained in Bode phase plot (Fig. 7b). This suggests that the addition of nano- $\mathrm{SiO}_{2}$ not only reduces the Warburg diffusion resistance but also improves the electron lifetime in the $\mathrm{TiO}_{2}$ electrode about two times.

The evolution of energy conversion efficiencies with time in days for both the cells with PVDF-HFP in absence and presence of $1 \%$ nano- $\mathrm{SiO}_{2}$, respectively, at room temperature are shown in Fig. 8 . The decrease in the efficiency of the DSSC containing $1 \%$ silica nanoparticles is $\sim 20 \%$ after 45 days, whereas that in the absence of $\mathrm{SiO}_{2}$, the energy loss is a lot (almost 1.8 times higher than the former) and this shows that the presence of $1 \%$ nano- $\mathrm{SiO}_{2}$ can improve the at-rest durability of the DSSC.

Furthermore, the influence of the DSSCs storage at $70^{\circ} \mathrm{C}$ was also analyzed. The chemical capacitance $\left(C_{\mu 2}\right)$ and charge transfer resistance $\left(R_{\mathrm{ct} 2}\right)$ of two cells with different GPEs storage at $70^{\circ} \mathrm{C}$ for a time period of 10 days evaluated by fitting the middle frequency semicircle in Nyquist plots measured under $100 \mathrm{~mW} \mathrm{~cm}^{-2}$, is pre-

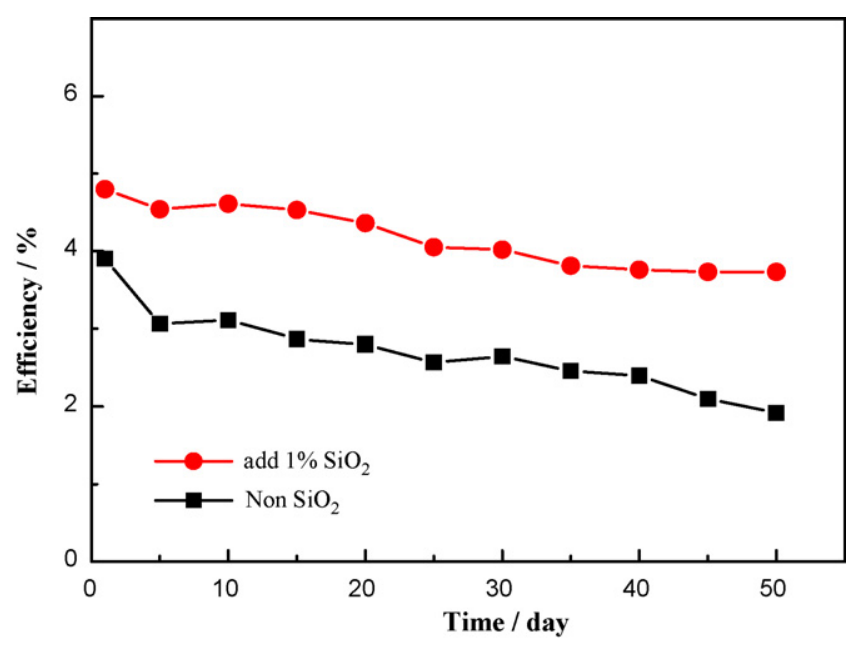

Fig. 8. At-rest stability of the DSSCs based on GPE with or without nano- $\mathrm{SiO}_{2}$. 


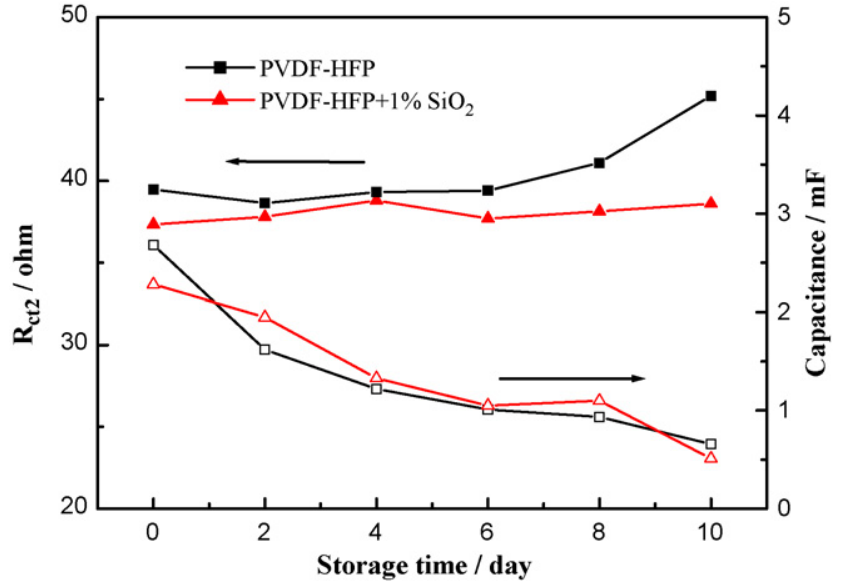

Fig. 9. The $R_{\mathrm{ct} 2}$ and capacitance of the DSSCs storage at $70^{\circ} \mathrm{C}$ for several days.

sented in Fig. 9. Thermal storage gives rise gently to an increase of the $R_{\mathrm{ct} 2}$ from 36 to $38 \Omega$ and 39 to $45 \Omega$, and decrease the $C_{\mu 2}$ from 2.2 to $0.5 \mathrm{mF}$ and 2.7 to $0.6 \mathrm{mF}$ for GPEs with and without nano- $\mathrm{SiO}_{2}$, respectively. This resulted in the shift of characteristic frequency peaks $(\mathrm{CF})$ of $\mathrm{TiO}_{2}$ to higher frequency, as shown in Fig. 10. It is clear from Bode phase plot that the electron lifetimes decrease obviously during thermal storage for the cells based on
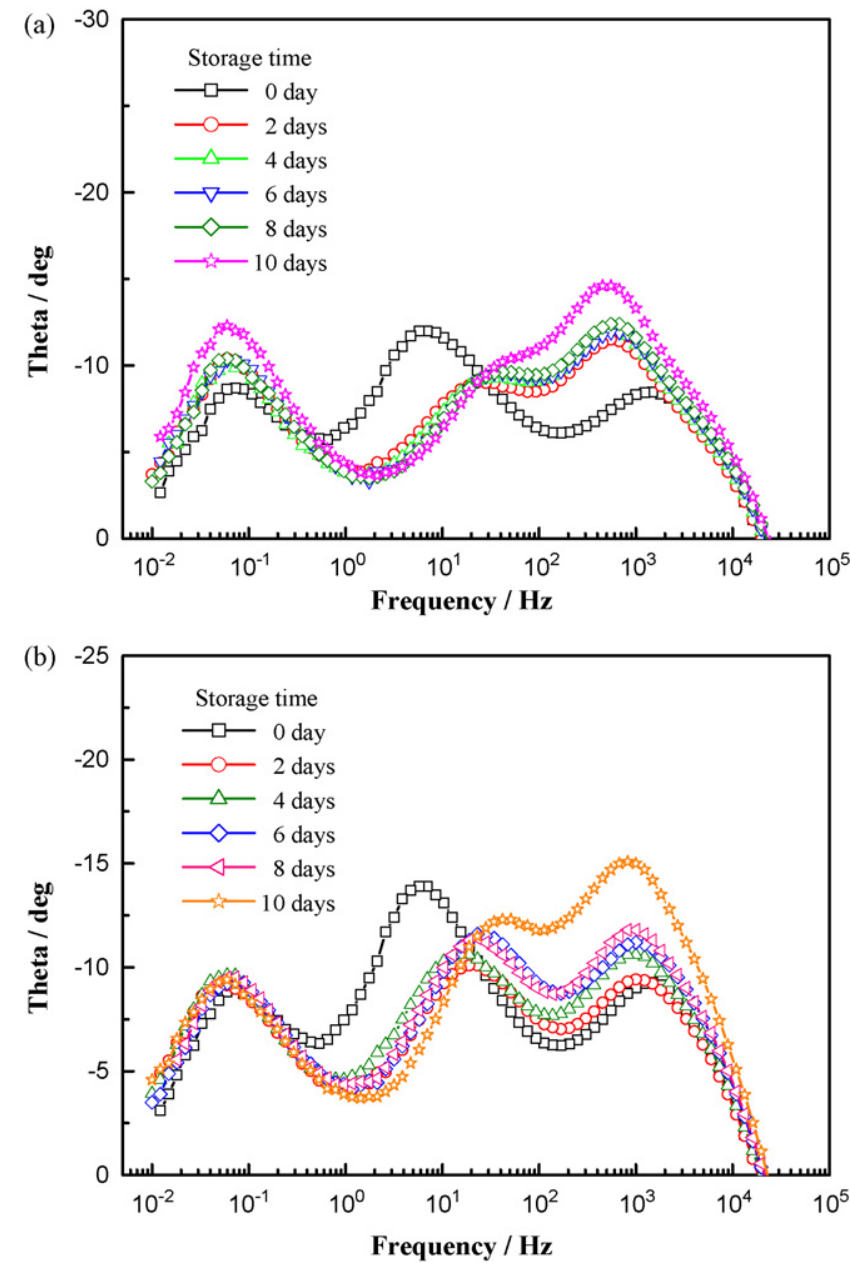

Fig. 10. Bode phase plots of the DSSCs based on (a) PVDF-HFP and (b) PVDF-HFP/1\% nano- $\mathrm{SiO}_{2}$ electrolytes, respectively, for the storage temperature at $70^{\circ} \mathrm{C}$.
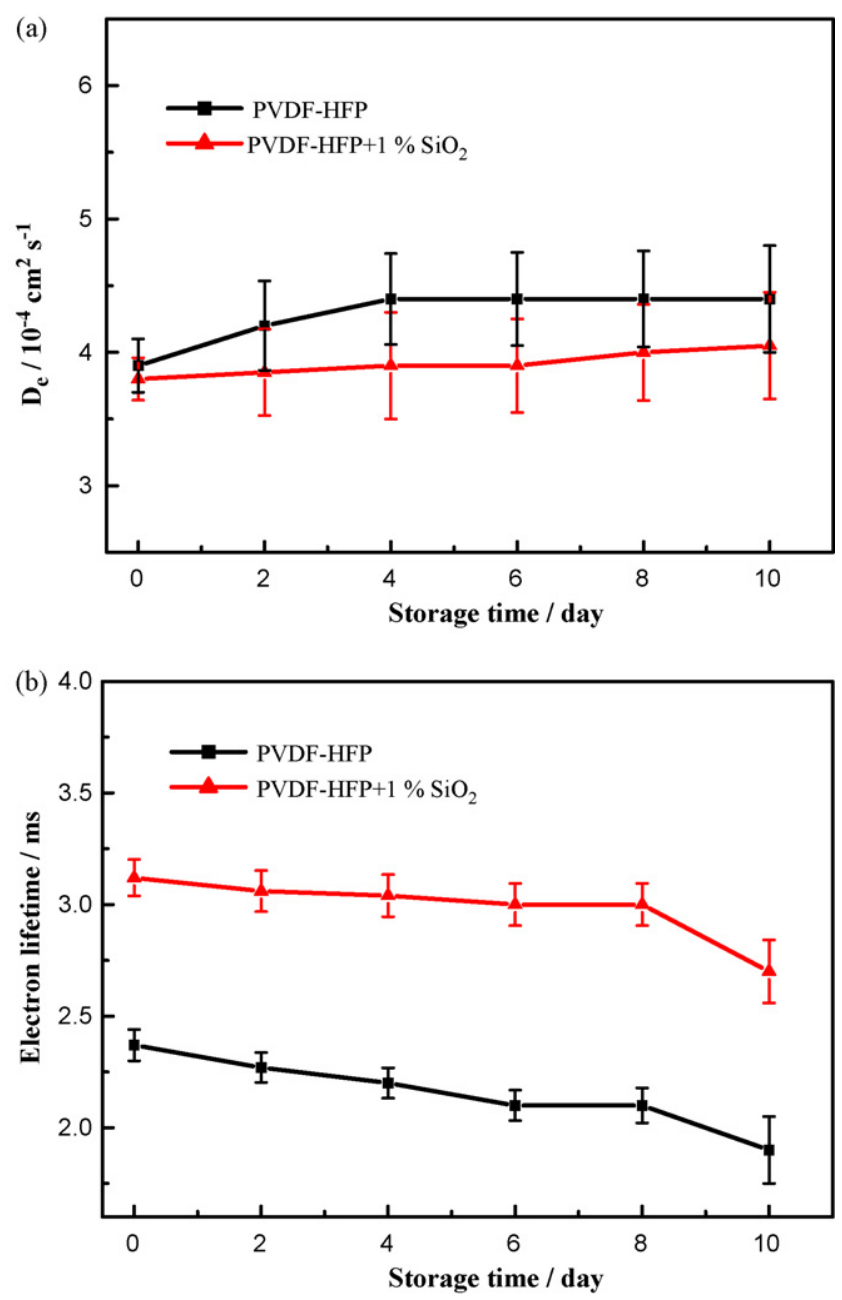

Fig. 11. Electron lifetimes and electron diffusion coefficients of the DSSCs based on (a) PVDF-HFP and (b) PVDF-HFP containing $1 \mathrm{wt} \%$ nano-SiO ${ }_{2}$ electrolytes, respectively, for the storage temperature at $70^{\circ} \mathrm{C}$

the two kinds of the GPEs. In addition, the redox reaction rate of $\mathrm{I}^{-} / \mathrm{I}_{3}^{-}$at Pt counter electrode surface also decreases with the storage time, especially for the absence of nano- $\mathrm{SiO}_{2}$ in GPE. This indicates that the GPE containing nano- $\mathrm{SiO}_{2}$ also leads the activation and better contact between Pt electrode and electrolyte. After thermal storage, the diffusion impedance becomes larger than that of the back reaction, leading to incomplete charge carrier collection due to the reduction of the effective electron diffusion length [46]. This resulted in the large drop of the photocurrent during thermal storage.

Furthermore, for comparison, the transient photovoltage and photocurrent measurements were also executed. Fig. 11a shows the electron diffusion coefficient $\left(D_{\mathrm{e}}\right)$ of the DSSCs based on two electrolytes at short-circuit state. The calculated $D_{\mathrm{e}}$ which is estimated from Eq. (1) increased gently with the storage time. The thermal stress led the increase of $D_{\mathrm{e}}$, however, a significant decrease of the electron lifetime $\left(\tau_{\mathrm{e}}\right)$ from 3.2 to $2.7 \mathrm{~ms}$ and 2.3 to $1.8 \mathrm{~ms}$ for DSSCs based on GPEs with and without nano-SiO 2 , respectively, was noted (Fig. 11b). This results in the short electron diffusion length after thermal storage, and this also supports the previous outcome. The electron lifetime obtained from transient photovoltage measurement shorter than that from EIS measurement is maybe due to the different light intensities and wavelengths used for these measurements. 


\section{Conclusion}

The effects of different weight percentages of PVDF-HFP containing various concentrations of $\mathrm{I}^{-}$and $\mathrm{I}_{2}$ along with TBP on the photovoltaic characteristics of the DSSCs were studied. In addition, the thermal storage of cells by EIS, transient photovoltage and photocurrent were also investigated. Adding silica nanoparticles into GPE as fillers can improve the performance and stability of the solar cell. The conversion efficiency of the solar cell with $5 \%$ of PVDF-HFP in MPN based on optimum concentration of $0.8 \mathrm{M}$ of TBAI and $0.12 \mathrm{M}^{\text {of } \mathrm{I}_{2}}$ is well comparable to that obtainable in liquid electrolyte and this is correlated with high conductivity of polymer electrolyte at the respective concentrations of TBAI and $\mathrm{I}_{2}$, as confirmed from EIS, and transient photovoltage and photocurrent measurements. Drastic improvements in the conductivity of PVDFHFP electrolyte at high concentration of $\mathrm{I}_{2}$ may be correlated with the formation of poly(iodide) along with part of contribution of ion-exchange diffusion. The addition of $1 \%$ of silica nanoparticles improves the cell performance and durability of the solar cell storage at both room temperature and at $70^{\circ} \mathrm{C}$. The electron lifetime and electron diffusion coefficient in the $\mathrm{TiO}_{2}$ film with GPE containing $1 \%$ of silica nanoparticle is higher and remains stable when compared to its absence.

\section{Acknowledgements}

This work was financially supported by the Academia Sinica, Taipei, Taiwan, the Republic of China, under grant AS-97-TP-A08. We also want to thank Professor King-Chuen Lin and his research group members, of Department of Chemistry, National Taiwan University, for the help in making the pulsed laser apparatus available to us.

\section{References}

[1] B. O’Reagen, M. Grätzel, Nature 353 (1991) 737.

[2] M. Grätzel, Nature 414 (2001) 338.

[3] A. Hagfeldt, M. Grätzel, Chem. Rev. 95 (1995) 49

[4] G.R.R.A. Kumara, A. Konno, G.K.R. Senadeera, P.V.V.D. Jayaweera, B.R.A. Silva, K. Tennakone, Sol. Energy Mater. Sol. Cells 69 (2001) 195

[5] B. O’Regan, D.T. Schwartz, S.M. Zakeeruddin, M. Grätzel, Adv. Mater. 12 (2000) 1263.

[6] J. Kruger, R. Plass, L. Cevey, M. Piccirelli, M. Grätzel, U. Bach, Appl. Phys. Lett. 79 (2001) 2085.

[7] K. Murakoshi, R. Kogure, Y. Wada, S. Yanagida, Sol. Energy Mater. Sol. Cells 55 (1998) 113.

[8] J. Hagen, W. Schaffrath, P. Otschik, R. Fink, A. Bacher, H.W. Schmidt, D. Haarer, Synth. Met. 89 (1997) 215.

[9] A.C. Arango, L.R. Johnson, V.N. Bliznyuk, Z. Schlesinger, S.A. Carter, H.H. Hörhold, Adv. Mater. 12 (2000) 1689

[10] F. Cao, G. Oskam, P.C. Searson, J. Phys. Chem. 99 (1995) 17071.

[11] G. Wang, X. Zhou, M. Li, J. Zhang, J. Kang, Y. Lin, S. Fang, X. Xiao, Mater. Res. Bull. 39 (2004) 2113

[12] M.A.K.L. Dissanayake, L.R.A.K. Bandara, R.S.P. Bokalawala, P.A.R.D. Jayathilaka, O.A. Illeperuma, S. Somasundaram, Mater. Res. Bull. 37 (2002) 867.
[13] O.A. Illeperuma, M.A.K.L. Dissanayake, S. Somasundaram, Electrochim. Acta 47 (2002) 2801

[14] O.A. Illeperuma, M.A.K.L. Dissanayake, S. Somasundaram, L.R.A.K. Bandara, Sol. Energy Mater. Sol. Cells 84 (2004) 117.

[15] J. Kang, W. Li, X. Wang, Y. Lin, X. Li, X. Xiao, S. Fang, J. Appl. Electrochem. 34 (2004) 301.

[16] G. Katsaros, T. Stergiopoulos, I.M. Arabatzis, K.G. Papadokostaki, P. Falaras, J. Photochem. Photobiol. A: Chem. 149 (2002) 191.

[17] T. Stergiopoulos, I.M. Arabatzis, G. Katsaros, P. Falaras, Nano Lett. 2 (2002) 1259.

[18] Y.J. Kim, J.H. Kim, M.S. Kang, M.J. Lee, J. Won, J.C. Lee, Y.S. Kang, Adv. Mater. 16 (2004) 1753.

[19] M. Masamitsu, M. Hiromitsu, M. Kikuo, K. Yoshimasa, T. Yoichi, Solid State Ion. 89 (1996) 263.

[20] Y. Liu, J.Y. Lee, L. Hong, J. Power Sources 129 (2004) 303.

[21] J.H. Kim, M.S. Sung, Y.J. Kim, J. Won, Y.S. Kang, Solid State Ion. 176 (2005) 579.

[22] P. Wang, S.M. Zakeeruddin, I. Exnar, M. Grätzel, Chem. Commun. (2002) 2972

[23] S.R. Scully, M.T. Lloyd, R. Herrera, E.P. Giannelis, G.G. Malliaras, Synth. Met. 144 (2001) 291.

[24] T. Kato, A. Okazaki, S. Hayase, Chem. Commun. (2005) 363.

[25] S. Murai, S. Mikoshiba, H. Sumino, T. Kato, S. Hayase, Chem. Commun. (2003) 1534.

[26] M.G. Kang, K.M. King, K.S. Ryu, S.H. Chang, N.G. Park, J.S. Hong, K.J. Kim, J Electrochem. Soc. 151 (2004) 257.

[27] P. Wang, S.M. Zakeeruddin, M. Grätzel, J. Fluorine Chem. 125 (2004) 1241.

[28] T. Asano, T. Kubo, Y. Nishikitani, J. Photochem. Photobiol. A: Chem. 164 (2004) 111.

[29] F.R.F. Fan, H.Y. Liu, A.J. Bard, J. Phys. Chem. 89 (1985) 4418.

[30] L. Kaven, M. Grätzel, Electrochim. Acta 34 (1989) 1327.

[31] M. Kosmulski, W. Janusz, J. Colloid Interface Sci. 242 (2001) 104

[32] P. Wang, S.M. Zakeeruddin, P. Comte, I. Exnar, M. Grätzel, J. Am. Chem. Soc. 125 (2003) 1166.

[33] N. Kopidakis, K.D. Benkstein, J. Van de Lagemaat, A.J. Frank, J. Phys. Chem. B 107 (2003) 11307.

[34] A. Solbrand, A. Henningsson, S. Sodergren, H. Lindstrom, A. Hagfeldt, S.E. Lindquist, J. Phys. Chem. B 103 (1999) 1078

[35] J. Van de Lagemaat, A.J. Frank, J. Phys. Chem. B 105 (2001) 11194.

[36] K.D. Benkstein, N. Kopidakis, J. Van de Lagemaat, A.J. Frank, J. Phys. Chem. B 107 (2003) 7759.

[37] M.K. Nazeeruddin, R. Humphry-Baker, P. Liska, M. Grätzel, J. Phys. Chem. B 107 (2003) 8981.

[38] C. Longo, J. Freitas, M.A. De Paoli, J. Photochem. Photobiol. A: Chem. 159 (2003) 33.

[39] M.C. Bernard, H. Cachet, P. Falaras, A. Hugot-Le Goff, M. Kalbac, I. Lukes, N.T Oanh, T. Stergiopoulos, I. Arabatzis, J. Electrochem. Soc. 150 (2003) E155.

[40] R. Koyima, L. Han, R. Yamanaka, A. Islam, T. Mitae, J. Photochem. Photobiol. A: Chem. 164 (2004) 123

[41] W. Kubo, K. Murakoshi, T. Kitamura, S. Yoshida, M. Haruki, K. Hanabusa, H. Shirai, Y. Wada, S. Yanagida, J. Phys. Chem. B 105 (2001) 12809.

[42] K. Hara, T. Horiguchi, T. Kinoshita, K. Sayama, H. Arakawa, Sol. Energy Mater Sol. Cells 70 (2001) 151.

[43] W. Kubo, S. Kambe, S. Nakade, T. Kitamura, K. Hanabusa, Y. Wada, S. Yanagida J. Phys. Chem. B 107 (2003) 4374.

[44] G. Krön, U. Rau, M. Durr, T. Miteva, G. Nelles, A. Yasuda, J.H. Werner, Electrochem. Solid-State Lett. 6 (2003) E11-E14.

[45] Q. Wang, J.E. Moser, M. Grätzel, J. Phys. Chem. B 109 (2005) 14945.

[46] G. Schlichthörl, S.Y. Huang, J. Sprague, A.J. Frank, J. Phys. Chem. B 101 (1997) 8141.

[47] Z. Li, G. Su, X. Wang, D. Gao, Solid State Ion. 176 (2005) 1903.

[48] A.M. Stephan, K.S. Nahm, T.P. Kumar, M.A. Kulandainathan, G. Ravi, J. Wilson, J. Power Sources 159 (2006) 1316.

[49] M.S. Kang, K.S. Ahn, J.W. Lee, J. Power Sources 180 (2008) 896

[50] J.Y. Song, Y.Y. Wang, C.C. Wan, J. Electrochem. Soc. 147 (2000) 3219. 